\title{
Frequencies Evaluation of $\beta$-Casein Gene Polymorphisms in Dairy Cows Reared in Central Italy
}

\author{
Carla Sebastiani ${ }^{1, *}$, Chiara Arcangeli ${ }^{1}$, Marcella Ciullo ${ }^{1}$, Martina Torricelli ${ }^{1}$, Giulia Cinti ${ }^{2}$, \\ Stefano Fisichella ${ }^{1}$ and Massimo Biagetti ${ }^{1, *(\mathbb{D})}$ \\ 1 Istituto Zooprofilattico Sperimentale dell'Umbria e delle Marche-Togo Rosati (IZSUM), Via Salvemini 1, \\ 06126 Perugia, Italy; c.arcangeli@izsum.it (C.A.); m.ciullo@izsum.it (M.C.); m.torricelli@izsum.it (M.T.); \\ s.fisichella@izsum.it (S.F.) \\ 2 R\&D Cooperlat, Società Cooperativa Agricola, via Piandelmedico 74, 60035 Jesi (Ancona), Italy; \\ g.cinti@trevalli.cooperlat.it \\ * Correspondence: c.sebastiani@izsum.it (C.S.); m.biagetti@izsum.it (M.B.)
}

Received: 9 January 2020; Accepted: 1 February 2020; Published: 5 February 2020

Simple Summary: Bovine milk contains several $\beta$-casein variants, with the $\mathrm{A} 1$ and $\mathrm{A} 2$ variants occurring most frequently. The presence of some variants, such as A1, B, and C, is considered a risk factor for disease in humans who consume milk. These variants are probably involved in intolerance to milk and some human diseases due to the production of a bioactive peptide with opioid activity during digestion, $\beta$-casomorphin 7 (BCM-7). In contrast, the $\mathrm{A} 2$ variant is not involved in pathogenetic mechanisms; thus, its presence in milk is a desirable feature. The difference between the $\mathrm{A} 1$ and $\mathrm{A} 2$ variants is a mutation at position 67 of the $\beta$-casein gene (CSN2), which causes an amino acid to change from histidine (in the $\mathrm{A} 1, \mathrm{~B}$, and $\mathrm{C}$ variants) to proline (in the $\mathrm{A} 2$ variant). To select dairy cows on the basis of the presence of the $\beta$-casein variant $A 2$, allele frequencies of CSN2 variants were evaluated in Italian dairy cows reared in central Italy. The results of this study may help with the selection of animals with the $\beta$-casein gene variant $\mathrm{A} 2$ to produce a more digestible milk that only contains the $\beta$-casein variant $A 2$.

Abstract: The majority of proteins in cow's milk are caseins, which occur in four groups ( $\alpha$-s1, $\alpha$-s2, $\beta$, and k) encoded by different genes (CSN1S1, CSN1S2, CSN2, and CSN3, respectively). In this study, we focused on the $\beta$-casein allele variants A1 and A2 due to their influence on milk's technological characteristics and human health. Digestion of the $\beta$-casein variant A1 leads to the formation of $\beta$-casomorphin 7 (BCM-7), a bioactive peptide that has been suggested to be a possible cause of various human diseases and associated with low milk digestibility. The potential negative role of the $\beta$-casein variant $A 1$ in human health has stimulated the planning of cattle breeding programs based on genetic selection to increase the frequency of the A2 variant, which is associated with increased milk digestibility. The aim of this work was to evaluate the frequencies of the different $\beta$-casein variants in Italian Holstein Friesian dairy cows from cattle farms located in central Italy to select a population of $\mathrm{A} 2$ homozygous animals. $\beta$-casein genotypes were identified by evaluating the presence of single nucleotide polymorphisms (SNPs) of the CSN2 gene using PCR and sequencing analysis. The frequency of the desirable $\beta$-casein variant $\mathrm{A} 2$ in the studied bovine population was 0.61 . The frequency of the undesirable A 1 variant in the studied bovine population was 0.30 . The frequency of the A2 allele was higher than expected for the breed; therefore, genetic selection for the A2 variant in these animals could be achieved in a fairly short time using A2 homozygous bulls.

Keywords: $\beta$-casein; polymorphisms; bovine; milk 


\section{Introduction}

Cow's milk is considered an important source of food for humans and plays a fundamental role in human health due to its valuable protein, fat-soluble vitamins, and mineral salt content, particularly calcium, which counteracts bone fragility and the risk of osteoporosis. Bovine milk is composed of $87 \%$ water, $3.68 \%$ lipids, $3.51 \%$ proteins, $4.98 \%$ lactose, and $0.74 \%$ microelements [1]. Of the proteins, the most important are caseins, which represent $82 \%$ of the total protein content [2]. Caseins are subdivided into four groups, $\alpha \mathrm{s} 1, \alpha \mathrm{s} 2, \beta$, and $\mathrm{k}$, respectively encoded by the CSN1S1, CSN1S2, CSN2, and CSN3 genes located on chromosome 6 [3]. The main function of caseins is the transport of calcium phosphate [4]. However, $\beta$-casein, which accounts for $36 \%$ of the total protein content, is also important for curd formation and determining the surface properties of micelles, which are useful features for cheese production [5,6]. Dairy cattle have $12 \beta$-casein variants (A1, A2, A3, B, C, D, E, F, H1, H2, I, and $G$ ); however, only seven of these (A1, A2, A3, B, C, I, and E) have been detected in European cattle breeds (Table 1) [7,8]. The A2 variant is considered the oldest variant, from which the others originated via mutation. The most common variants are A1 and A2; the B variant is less common [9]. The I variant is usually detected at low frequencies [8], the A3 and C variants are rare [9], the E variant is detectable only in the Italian Piedmontese breed [10], and the F variant has been detected in the Emilia Romagna region (Northern Italy) at a very low frequency (0.006) [8]. The difference between the $\mathrm{A} 1$ and $\mathrm{A} 2$ variants is due to a mutation in position 67 , which causes an amino acid to change from histidine (in the A1, B, and C variants) to proline (in the A2, A3, E, and I variants). The allele variants $A 1, B$, and $C$ differ from each other with respect to an amino acid in position 122 (serine in $A 1$ and $C$, arginine in $B$ ) and one in position 37 (glutamic acid in the A1 and B variants and lysine in the C variant). The I and A3 variants were derived from a mutation of the A2 variant; specifically, the I variant has a leucine instead of a methionine in position 93 and the A3 variant has a glutamine instead of a histidine in position 106. To summarize, the A1 and A3 variants originated from the A2 variant; subsequently, the I variant was derived from the A3 variant, and the B and C variants were derived from the A1 variant. Each variant exhibits the same behavior as the variants from which it arose in terms of $\beta$-casomorphin 7 (BCM-7) formation [11] (Table 1).

Table 1. The change in the amino acid sequence of $\beta$-casein variants (in bold: amino acid variations).

\begin{tabular}{|c|c|c|c|c|c|c|c|c|c|}
\hline \multirow{2}{*}{$\begin{array}{l}\beta \text { casein } \\
\text { Variant }\end{array}$} & \multicolumn{9}{|c|}{ Amino Acid Position } \\
\hline & 36 & 37 & 67 & 72 & 88 & 93 & 106 & 122 & 138 \\
\hline $\mathrm{A} 2 *$ & Glu (E) & Glu (E) & Pro $(\mathrm{P})$ & $\mathrm{Gln}(\mathrm{Q})$ & Leu (L) & $\operatorname{Met}(\mathrm{M})$ & His $(\mathrm{H})$ & Ser $(S)$ & Pro $(\mathrm{P})$ \\
\hline $\mathrm{A} 1$ * & Glu (E) & Glu (E) & His $(\mathrm{H})$ & $\mathrm{Gln}(\mathrm{Q})$ & Leu (L) & Met (M) & His $(\mathrm{H})$ & Ser $(S)$ & Pro $(\mathrm{P})$ \\
\hline $\mathrm{A} 3$ * & Glu (E) & Glu (E) & Pro $(\mathrm{P})$ & $\mathrm{Gln}(\mathrm{Q})$ & Leu (L) & Met (M) & $\mathrm{Gln}(\mathrm{Q})$ & Ser $(S)$ & Pro $(\mathrm{P})$ \\
\hline $\mathrm{B}^{*}$ & Glu (E) & Glu (E) & His $(\mathrm{H})$ & $\mathrm{Gln}(\mathrm{Q})$ & Leu (L) & Met (M) & His $(\hat{\mathrm{H}})$ & $\operatorname{Arg}(\mathrm{R})$ & Pro $(\mathrm{P})$ \\
\hline$C^{*}$ & Glu (E) & Lys (K) & His $(\mathrm{H})$ & $\mathrm{Gln}(\mathrm{Q})$ & Leu (L) & $\operatorname{Met}(\mathrm{M})$ & His $(\mathrm{H})$ & Ser $(S)$ & Pro $(\mathrm{P})$ \\
\hline$E^{*}$ & Lys (K) & Glu (E) & Pro $(\mathrm{P})$ & $\mathrm{Gln}(\mathrm{Q})$ & Leu (L) & $\operatorname{Met}(\mathrm{M})$ & His $(\mathrm{H})$ & Ser $(S)$ & Pro $(\mathrm{P})$ \\
\hline$I^{*}$ & Glu (E) & Glu (E) & Pro $(\mathrm{P})$ & $\mathrm{Gln}(\mathrm{Q})$ & Leu (L) & Leu (L) & His $(\mathrm{H})$ & Ser $(S)$ & Pro $(\mathrm{P})$ \\
\hline $\mathrm{D}$ & Glu (E) & Glu (E) & Pro $(\mathrm{P})$ & Gln (Q) & Leu (L) & Met (M) & His $(\mathrm{H})$ & Ser $(S)$ & Pro $(\mathrm{P})$ \\
\hline $\mathrm{F}$ & Glu (E) & Glu (E) & His $(\mathrm{H})$ & $\mathrm{Gln}(\mathrm{Q})$ & Leu (L) & Met (M) & His $(\mathrm{H})$ & Ser $(S)$ & Leu (L) \\
\hline G & Glu (E) & Glu (E) & His $(\mathrm{H})$ & Gln (Q) & Leu (L) & Met (M) & His $(\mathrm{H})$ & Leu (L) & Pro $(\mathrm{P})$ \\
\hline $\mathrm{H} 1$ & Glu (E) & Glu (E) & Pro (P) & $\mathrm{G} \ln (\mathrm{Q})$ & Ile (I) & $\operatorname{Met}(\mathrm{M})$ & His $(\mathrm{H})$ & Ser (S) & Pro $(\mathrm{P})$ \\
\hline $\mathrm{H} 2$ & Glu (E) & Glu (E) & Pro $(\mathrm{P})$ & Glu (E) & Leu (L) & Leu (L) & His $(\mathrm{H})$ & Ser (S) & Glu (E) \\
\hline
\end{tabular}

Arg: arginine; Gln: glutamine; Glu: glutamic acid; His: histidine; Ile: isoleucine; Leu: leucine; Lys: lysine; Met: methionine; Pro: proline; Ser: serine; * Allele variants detected in European cattle breeds.

We paid particular attention to the allele variants A1 and A2 due to their influence on milk's technological characteristics and implications for human health. The A1 variant improves curd consistency, milk coagulation, and micelle size, but results in lower milk digestibility compared with the $A 2$ variant [12]. The $\beta$-casein variants $A 1$ and A2 are differently processed; digestive enzymes are able to perform a proteolytic cleavage of the $\beta$-casein chain when a histidine is present at position 67 
to form a peptide of seven amino acids named $\beta$-casomorphine 7 (BCM-7). Evidence showed that BCM-7 has strong opioid activity with an additional oxidizing effect and can interact with endogenous opioid systems at the gastrointestinal wall in both newborns and adults [13]. According to Deth et al. (14), consumption of milk containing the A2 variant increases the natural production of glutathione (GSH), an antioxidant that is widely recognized for its association with a series of health benefits. The study showed that the consumption of milk containing only the A2 variant increases the GSH level in the blood to approximately twice the level associated with the consumption of milk containing both the $\beta$-casein variants A1 and A2 [14]. Therefore, the allele variants that are considered risk factors for human disease are those that contain a histidine in position 67 (A1, B, and C variants), whereas those that contain a proline, i.e., the $\mathrm{A} 3$ and I variants, behave like the $\mathrm{A} 2$ variant even though they contain other single-nucleotide polymorphisms (SNPs) in position 106 (histidine to glutamine) and position 93 (methionine to leucine), respectively. Some studies reported a correlation between the consumption of milk containing the $\beta$-casein variant $A 1$ and heart disease, sudden infant death syndrome, and aggravation of symptoms associated with schizophrenia, autism, type 1 diabetes, and milk intolerance [15-20].

In contrast, a scientific report of the European Food Safety Authority (EFSA) in 2009 concluded that no cause-effect relationship exists between the consumption of milk containing the A1 variant and the etiology of the abovementioned diseases and that further investigations are necessary [13]. More recently, a scientific report highlighted a lack of a correlation between adverse human health effects and consumption of the $\beta$-casein variant $A 1$ in comparison to the $\beta$-casein variant $A 2$ [21].

Therefore, the discussion on the adverse human health effects of the $\beta$-casein variant $\mathrm{A} 1$ remains open. However, milk obtained from cows with the A2/A2 genotype seems to be more digestible than milk obtained from cows with the A1 genotype in terms of an increase in gastrointestinal transit [12]. A2 cow's milk, or milk without the A1 variant, is commercially available in a number of countries, including Australia, the United Kingdom, the United States, New Zealand, and the Netherlands, and is widely recommended for people who are milk-intolerant. Formula for newborns that contains the $\beta$-casein variant A2 is now sold in China and Australia and is promoted commercially as being more gentle on an infant's digestive system [12]. The potential negative role of the $\beta$-casein variant A1 in human health has stimulated the planning of cattle breeding programs based on the selection of $\beta$-casein gene polymorphisms.

The purpose of this work was to evaluate the frequency of occurrence of different $\beta$-casein variants in dairy cows from cattle farms in central Italy that supply milk to an important drinking-milk-producing plant, with the aim of selecting a population of A2 homozygous animals and commercializing an A2 milk that only contains the $\beta$-casein variant A2.

\section{Materials and Methods}

A total of 1629 whole blood samples were collected from Italian Holstein Friesian cows from 17 farms located in central Italy. The samples were collected in tubes containing Ethylenediaminetetra-acetic acid (EDTA) as an anticoagulant and stored at $-20{ }^{\circ} \mathrm{C}$ until analysis. The samples were taken in a single withdrawal, at the same time of the mandatory periodic tests required by Italian National Health Programs and during farmer's voluntary health controls. Genomic DNA was extracted using a High Pure PCR Template Preparation Kit (Roche Life Science, Mannheim, Germany) according to the manufacturer's instructions. Specific primers for the exon 6 and 7 portions of the CSN2 gene were selected from the literature [22] and modified using Primer Express®v3.0.1 software (Applied Biosystems; Thermo Fisher Scientific Inc., Waltham, MA, USA) to increase the efficiency of the assay (Table 2). 
Table 2. Primer sequences (For, forward primer; Rev, reverse primer).

\begin{tabular}{ccccc}
\hline \multirow{2}{*}{ Target Gene } & $\begin{array}{c}\text { Target } \\
\text { Sequence }\end{array}$ & Primer Sequences & $\begin{array}{c}\text { Amplification } \\
\text { Product (bp) }\end{array}$ & Reference \\
\hline \multirow{2}{*}{ CSN2 } & Exon 6 & $\begin{array}{c}\text { For CATCAATAAGGTAAAACCCCTCATATT } \\
\text { Rev TTGTCAAAGTTTTATTTCTTGCACTG }\end{array}$ & 274 & \multirow{2}{*}{ This study } \\
\cline { 2 - 4 } & Exon 7 & $\begin{array}{c}\text { For TTTCCAGGATGAACTCCAGGAT } \\
\text { Rev CATCAGAAGTTAAACAGGCACAGTTAG }\end{array}$ & 547 & \\
\hline
\end{tabular}

The PCR was set up in a total reaction volume of $50 \mu \mathrm{L}$ as follows: for exon 6, 1.5 X GoTaq®Flexi Buffer, $1 \mathrm{mM} \mathrm{MgCl} 2,2.5 \mathrm{U}$ of GoTaq®G2 Flexi DNA Polymerase (Promega Corporation, Madison, WI, USA), $200 \mu \mathrm{M}$ dNTPs (GE Healthcare, Buckinghamshire, England), $0.3 \mu \mathrm{M}$ of each primer (Invitrogen; Thermo Fisher Scientific Inc., Waltham, MA, USA) (Table 2), and $4 \mu \mathrm{L}$ of the extracted DNA template; for exon 7, 1 X GoTaq $® F l e x i$ Buffer, $1.5 \mathrm{mM} \mathrm{MgCl}_{2}$, $2.5 \mathrm{U}$ of GoTaq $\circledast$ G2 Flexi DNA Polymerase (Promega Corporation) $200 \mu \mathrm{M}$ dNTPs (GE Healthcare), $0.2 \mu \mathrm{M}$ of each primer (Invitrogen; Thermo Fisher Scientific Inc.) (Table 2) and $2 \mu \mathrm{L}$ of the extracted DNA template.

PCR amplifications for both protocols were conducted on a Mastercycler Ep Gradient S (Eppendorf AG, Hamburg, Germany) with the following thermal cycling profile: an initial denaturation at $95^{\circ} \mathrm{C}$ for $10 \mathrm{~min}$, followed by 35 cycles at $95^{\circ} \mathrm{C}$ for $1 \mathrm{~min}, 58^{\circ} \mathrm{C}$ for $1 \mathrm{~min}, 72^{\circ} \mathrm{C}$ for $1 \mathrm{~min}$, and a final elongation step at $72{ }^{\circ} \mathrm{C}$ for $7 \mathrm{~min}$. Amplification products were analyzed by electrophoresis on 2\% agarose gel containing Midori Green Advanced DNA Stain (Nippon Genetics Europe GmbH, Düren, Germany) and purified with a QIAquick®PCR Purification Kit (Qiagen, Hilden, Germany), according to the manufacturer's instructions. Sequencing reactions were completed for both strands using a BrilliantDye ${ }^{\mathrm{TM}}$ Terminator Cycle Sequencing Kit v3.1 (NimaGen BV, Nijmegen, The Netherlands) according to the manufacturer's instructions with the same primers that were used for PCR amplification. Sequencing reactions were analyzed in a 3500 Genetic Analyzer (Applied Biosystems; Thermo Fisher Scientific Inc.). Sequences were then aligned to the bovine $\beta$-casein gene (Accession number X14711.1) with the ClustalW tool of the BioEdit v7.2.5 software [23]. Electropherograms were checked at each investigated mutation point to identify heterozygous peaks indicating the presence of both alleles. The polymorphisms at positions 36 and 37 of exon 6 and positions $67,72,88,93,106,122$, and 138 of exon 7 were analyzed to discriminate between the different $\beta$-casein variants.

Allele and genotype frequencies were directly calculated dividing the number of copies of each allele and genotype by the total alleles and by the total individuals, respectively. The Hardy-Weinberg (HW) equilibrium was verified using Chi-square test $(p<0.05)$ by Genalex 6.5 software [24,25].

\section{Results and Discussion}

The main goal of our study was to evaluate the frequency of occurrence of the $\beta$-casein CSN2 gene alleles in dairy cattle of the Italian Holstein Friesian breed reared in central Italy. We paid particular attention to the frequencies of the A2 variant and its related genotypes given its association with health benefits. Although the Italian Holstein Friesian breed is not among those breeds characterized by the highest frequency of the A2/A2 genotype, it has a sufficiently high frequency to allow for effective genetic selection of this feature [26]. Therefore, the estimation of allele and genotype frequencies is important for planning an efficacious genetic selection program for these animals with the final goal of producing A2 cow's milk. Our results show the distribution of the allele and genotype frequencies of the different CSN2 gene variants in the population under study. Considering the polymorphic sites evaluated in this study, all the alleles conformed to the HW equilibrium and no deviation was detected.

The sequencing analysis performed in both directions on the PCR products showed that, of the nine considered polymorphic sites spanning the regions of exons 6 and 7 of the CSN2 gene, a total of five were polymorphic: E37K, P67H, M93L, H106Q, and S122R (Table 1). They produced six $\beta$-casein variants (A1, A2, A3, B, C, and I) in 13 genotypes, 3 of which were homozygous (A1/A1, A2/A2, 
and B/B) and 10 of which were heterozygous (A1/A2, A1/A3, A1/B, A1/C, A1/I, A2/A3, A2/B, A2/I, A3/B, and $\mathrm{B} / \mathrm{I}$ ) as shown in Table 3 .

Table 3. The allele and genotype frequencies (\%) in the examined animals (the data are sorted by decreasing allele and genotype frequency).

\begin{tabular}{cccc}
\hline Allele & Allele Frequency $\mathbf{( \% )}$ & Genotype & Genotype Frequency (\%) \\
\hline A2 & 60.65 & A2/A2 & 36.96 \\
A1 & 30.39 & A1/A2 & 35.79 \\
B & 5.68 & A1/A1 & 9.88 \\
I & 3.10 & A2/B & 7.55 \\
A3 & 0.15 & A2/I & 3.93 \\
C & 0.03 & A1/B & 3.07 \\
& & A1/I & 2.03 \\
& & B/I & 0.25 \\
& & B/B & 0.18 \\
& & A2/A3 & 0.12 \\
& & A3/B & 0.12 \\
& & A1/C & 0.06 \\
\end{tabular}

The A2 allele was the most commonly found, with a frequency of $60.65 \%$, followed by the A1 allele with a frequency of $30.39 \%$, the B allele at $5.68 \%$, the I allele at $3.10 \%$, the A3 allele at $0.15 \%$, and the $\mathrm{C}$ allele with a frequency of $0.03 \%$. These results agree with those reported from a study conducted in cattle of the same breed from farms located in the Emilia Romagna region (Northern Italy) by Massella et al. (8), who found a high frequency of the A2 allele (54.6\%), followed by the A1 (37.1\%), B (5.0\%), I (2.7\%), and F (0.6\%) alleles.

In our samples, we did not observe the $\mathrm{F}$ variant, which is very rare and for which few data are available about its frequency in milk-producing breeds [8]. We did not find the E variant, which, to date, has only been observed in the Piemontese breed [27] or the D, G, H1, and H2 variants, which have never been found in European breeds [7]. These results are also consistent with those reported by Kaminsky et al. (16), which showed that the A1 and A2 variants are the most common in the Holstein Friesian breed.

Regarding the genotype, the homozygous genotype A2/A2 was the most common, with a frequency of $36.96 \%$, followed by the heterozygous genotypes A1/A2 and A1/A1 with frequencies of $35.79 \%$ and $9.88 \%$, respectively. The remaining genotypes showed lower frequencies that ranged from $7.55 \%(\mathrm{~A} 2 / \mathrm{B})$ to $0.06 \%$ (A1/A3-A1/C) (Table 3). A total of $2.46 \%$ of the examined animals were found to carry the A3 and I variants (A1/I, B/I, A3/B, and A1/A3), while $4 \%$ were A2/A3 and A2/I. These individuals could be considered as $\mathrm{A} 2$ heterozygous and homozygous, respectively.

A breed is considered suitable for selection of the A2 allele if its frequency is close to $50 \%$. In this case, given the Mendelian inheritance of the trait and presuming that the population is in Hardy-Weinberg equilibrium, in the herd we would expect to find 25\% homozygous A1/A1 animals, $50 \%$ A1/A2 heterozygotes, and 25\% A2/A2 homozygous individuals, and that the produced bulk milk contains 50\% $\beta$-casein variant A1 and 50\% $\beta$-casein variant A2 [26]. To change the herd's composition with the aim of producing a milk containing only the $\beta$-casein variant A2, A2/A2 bulls must be used for the artificial insemination of A2 carrier cows. The Italian Holstein Friesian breed provides an appropriate genetic background for increasing the frequency of this favorable allele through appropriate breeding.

In the farms analyzed, we found an A2 allele frequency of $60.65 \%$, slightly greater than those reported in the recent literature (8). The presence of other variants similar to A2 (A3 and I), relative to BMC-7 production, accounting for another 3.25\%, increased the frequency of favorable variants to $64 \%$. Consequently, we found high frequencies of A2/A2 individuals (37\%) and A2 heterozygous carriers (47.4\%). As the A3 and I variants behave similarly to the A2 variant, the percentage of A2/A2-like 
genotypes (A2/A2, A2/A3, and A2/I) was 41\%, increasing the overall percentage of genotypes with at least one A2-like allele to $87 \%$.

\section{Conclusions}

In this study, we focused on the $\beta$-casein variants A1 and A2 due to their influence on milk's technological characteristics and their implications for human health. The $\beta$-casein variant A2 is desirable in milk because it increases the digestibility of milk. A2 cow's milk can be immediately produced in a herd if the cows present on farms are screened to identify animals with the A2/A2 genotype and the milk of these individuals is separated from that of the others. The identification of A2 carrier cows then allows the planning of animal couplings with the aim of generating A2 homozygous progenies. In conclusion, genotyping by sequencing is a fast and reliable method for monitoring the allele frequencies of $\beta$-casein variants in a population of dairy cows where selection of the $\beta$-casein variant $\mathrm{A} 2$ is the aim.

Marker-assisted selection (MAS) should be applied to align Italian dairy breeds with those of other countries that have already invested in A2 cow's milk production. In many countries, A2 cow's milk has already been commercialized as a product with beneficial properties with a resulting economic gain.

These data will allow us to manage animal couplings to increase the frequency of the favorable A2 allele, simultaneously decrease the frequency of undesirable alleles, and finally create herds of A2/A2 animals from the population of dairy cow breeds oriented to A2 cow's milk production.

Author Contributions: Conceptualization, S.F., G.C., and M.B.; methodology, C.S. and M.B.; formal analysis, C.A. and C.S.; investigation, C.A., M.C., M.T., and C.S.; resources, G.C., and S.F.; writing-original draft preparation, C.A.; writing-review and editing, M.B., C.S., S.F., and G.C.; supervision, M.B. and C.S.; project administration, M.B. and S.F.; funding acquisition, S.F. and G.C. All authors have read and agreed to the published version of the manuscript.

Funding: This research was funded by Progetto Stalla 20.20-ID Progetto n. 21999-Misura 16.2-PSR Marche 2014-2020-Filiera Agro-Alimentare n. 497-Coordinator: Cooperlat Soc. Coop. Agr.

Conflicts of Interest: The authors declare no conflicts of interest. The funders had no role in the design of the study; in the collection, analyses, or interpretation of data; in the writing of the manuscript, or in the decision to publish the results.

\section{References}

1. Jenness, R. Comparative aspects of milk protein. J. Dairy Res. 1979, 46, 197-210. [CrossRef] [PubMed]

2. Tailford, K.A.; Berry, C.L.; Thomas, A.C.; Campbell, J.H. A casein variant in cow's milk is atherogenic. Atherosclerosis 2003, 170, 13-19. [CrossRef]

3. Rijnkels, M. Multispecies comparison of the casein gene loci and evolution of casein gene family. J. Mammary Gland Biol. Neoplasia 2002, 7, 327-345. [CrossRef] [PubMed]

4. Stewart, A.F.; Bonsing, J.; Beattie, C.W.; Shah, F.; Willis, I.M.; Mackinlay, A.G. Complete nucleotide sequences of bovine $\alpha$ s 2 and $\beta$-casein cDNAs: Comparisons with related sequences in other species. Mol. Biol. Evol. 1987, 4, 231-241. [CrossRef] [PubMed]

5. Pearse, M.J.; Linklater, P.M.; Hall, R.J.; Macaulay, A.G. The effect of casein composition and casein dephosphorylation on the coagulation and synthesis of artificial micelle milk. J. Dairy Res. 1986, 53, 381-390. [CrossRef]

6. Ng-KwayHang, K.F. Genetic variants of milk proteins and their effects on the yield and quality of cheese. CAB Reviews: Perspectives in Agriculture, Veterinary Science, Nutrition and Natural Resources 2006, 56, 1-11. [CrossRef]

7. Barroso, A.; Dunner, S.; Cañón, J. Technical note: Use of PCR-single-strand conformation polymorphism analysis for detenction of bovine $\beta$ - casein variants A1, A2, A3, B.J. Anim. Sci. 1999, 77, 2629-2632. [CrossRef]

8. Massella, E.; Piva, S.; Giacometti, F.; Liuzzo, G.; Zambrini, A.V.; Serraino, A. Evaluations of bovine $\beta$ - casein polymorphism in two dairy farms located in northern. Ital. J. Food Safety 2017, 6, 6904. [CrossRef]

9. Farrel, H.M.; Jimenez-Flores, R.; Bleck, G.T.; Brown, E.M.; Butler, J.E.; Creamer, L.K.; Swaisgood, H.E. Nomenclature of the proteins of cows' milk—sixth revision. J. Dairy Sci. 2004, 87, 1641-1674. [CrossRef] 
10. Voglino, G.F. A new $\beta$ - casein variant in piedmont cattle. Anim. Genet. 1972, 3, 61-62. [CrossRef]

11. Bodnár, Á.; Hajzser, A.; Egerszegi, I.; Póti, P.; Kuchtík, J.; Pajor, F. A2 milk and its importance in dairy production and global market. Anim. Welf. 2018, 14, 1-7.

12. Brooke-Taylor, S.; Dwyer, K.; Woodford, K.; Kost, N. Systematic Review of the Gastrointestinal Effects of A1 Compared with A2 $\beta$-Casein. Adv. Nutr. 2017, 15, 739-748. [CrossRef] [PubMed]

13. European Food Safety Authority. Review of the potential health impact of $\beta$-casomorphins and related peptides. EFSA Sci. Rep. 2009, 231, 1-107.

14. Deth, R.; Andrew Clarke, A.; Jiayi, N.J.; Trivedi, M. Clinical evaluation of glutathione concentrations after consumption of milk containing different subtypes of $\beta$-casein: Results from a randomized, cross-over clinical trial. Nutr. J. 2016, 15, 82-87. [CrossRef] [PubMed]

15. McLachlan, C.N. $\beta$-casein A1, ischaemic heart disease mortality and other illnesses. Med. Hypotheses 2001, 56, 262-272. [CrossRef]

16. Kamiński, S.; Cieślińska, A.; Kostyra, E. Polymorphism of bovine $\beta$-casein and its potential effect on human health. J. Appl. Genet. 2007, 48, 189-198. [CrossRef]

17. Caroli, A.M.; Chessa, S.; Erhardt, G.J. Invited review: Milk protein polymorphism in cattle: Effect on animal breeding and human nutrition. J. Dairy Sci. 2009, 92, 5335-5352. [CrossRef]

18. Pal, S.; Woodford, K.; Kukuljan, S.; Ho, S. Milk intolerance, $\beta$ - casein and lactose. Nutrients 2015, 7, $285-297$. [CrossRef]

19. Cieslinska, A.; Sienkiewicz-Szłapka, E.; Wasilewska, J.; Fiedorowicz, E.; Chwała, B.; Moszy'nska-Dumara, M.; Kostyra, E. Influence of candidate polymorphisms on the dipeptidyl peptidase IV and $\mu$-opioid receptor genes expression in aspect of the $\beta$-casomorphin-7 modulation functions in autism. Peptides 2015, 65, 6-11. [CrossRef]

20. Reichelt, K.L.; Tveiten Bioengineer, D.; Knivsberg, A.M.; Brønstad, G. Peptides' role in autism with emphasis on exorphins. Microb. Ecol. Health Dis. 2012, 23, 18958. [CrossRef]

21. Kullenberg de Gaudry, D.; Lohner, S.; Schmucker, C.; Kapp, P.; Motschall, E.; Horrlein, S.; Roger, C.; Meerpohl, J.J. Milk A1 b-casein and health-related outcomes in humans: A systematic review. Nutr. Rev. 2019, 77, 278-306. [CrossRef] [PubMed]

22. Chessa, S.; Chiatti, F.; Ceriotti, G.; Caroli, A.; Consolandi, C.; Pagnacco, G.; Castiglioni, B. Development of a Single Nucleotide Polymophism genotyping microarray platform for the identification of bovine milk protein genetic polymorphisms. J. Dairy Sci. 2007, 90, 451-464. [CrossRef]

23. Hall, T.A. BioEdit: A user-friendly biological sequence alignment editor and analysis program for Windows 95/98/NT. Nucleic Acids Symp. Ser. 1999, 41, 95-98.

24. Peakall, R.; Smouse, P.E. GENALEX 6: Genetic analysis in Excel. Population genetic software for teaching and research. Mol. Ecol. Notes 2006, 6, 288-295. [CrossRef]

25. Peakall, R.; Smouse, P.E. GenAlEx 6.5: Genetic analysis in Excel. Population genetic software for teaching and research-an update. Bioinformatics 2012, 28, 2537-2539. [CrossRef]

26. Canavesi, F. Selezionare per produrre latte A2. Professione Allevatore 2016, 16, 52-54.

27. Jann, O.; Ceriotti, G.; Caroli, A.; Ethardt, G. A new variant in exon VII of bovine $\beta$-casein gene (CSN2) and its distribution among European cattle breeds. J. Anim. Breed. Genet. 2002, 119, 65-68. [CrossRef]

(C) 2020 by the authors. Licensee MDPI, Basel, Switzerland. This article is an open access article distributed under the terms and conditions of the Creative Commons Attribution (CC BY) license (http://creativecommons.org/licenses/by/4.0/). 